\title{
OVERVIEW OF COGNITIVE FUNCTION IN THE ELDERLY WITH VARIATIONS OF TOTAL REMAINING TEETH REVIEW FROM MINI- MENTAL STATE EXAMINATION
}

\author{
Ifwandi ${ }^{1}$ (D), Dewi Saputri ${ }^{1}$ (D), Liana Rahmayani ${ }^{1} 凹$ (D), Pocut Aya Sofya ${ }^{1}$, Syahrial ${ }^{1}$, Zelcha Savira \\ Haridhi 1 iD
}

${ }^{1}$ Faculty of Dentistry, Universitas Syiah Kuala, Banda Aceh 23111, Indonesia.

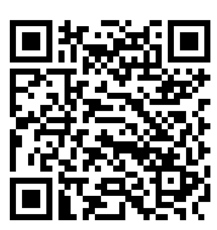

Received 17 October 2021

Accepted 5 November 2021

Published 30 November 2021

CorrespondingAuthor

Liana Rahmayani,

liana.rahmayani@unsyiah.ac.id

DOI

10.29121/granthaalayah.v9.i11.2021 .4389

Funding: This research received no specific grant from any funding agency in the public, commercial, or not-for-profit sectors.

Copyright: (C) 2021 The Author(s). This is an open access article distributed under the terms of the Creative Commons Attribution License, which permits unrestricted use, distribution, and reproduction in any medium, provided the original author and source are credited.

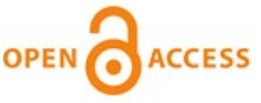

\begin{abstract}
When a person reaches the elderly phase, the function of the body's organs decreases, which causes an increased risk of disease and death. Including dental infections such as caries and periodontal disease which are the main factors for tooth loss. Tooth loss does not only affect the impact of mastication but also affects a person's cognitive function. This condition occurs because when a person loses teeth, the function of the Periodontal Mechanoreceptors decreases, disrupting the function of the hippocampus which is important for memory in the brain. Loss of a large number of teeth tends to indicate low cognitive function, but several factors affect cognitive function, namely education level, Diabetes Mellitus, Hypertension, heart disease, depression, sleep disorders, head injury, physical activity, and a history of smoking. Mini-Mental State Examination (MMSE) is a tool to assess a person's cognitive function. This study aims to see the description of cognitive function in the elderly at the Geunaseh Sayang Nursing Home with variations in the number of tooth losses. This study was conducted with 43 research subjects with interviews and intra-oral examination methods. Based on the results of the study, it can be concluded that the elderly who only have fewer teeth show a higher decline in cognitive function compared to the elderly with more teeth in the oral cavity. This is following the theory which states that the more teeth you lose, the lower your cognitive function will be.
\end{abstract}

Keywords: Elderly, Cognitive Function, Mini-Mental State Examination (MMSE), Periodontal Mechanoreceptors (Pdms), Hippocampus

\section{INTRODUCTION}

Elderly means occupying the peak of the human life cycle which is interrelated between phases, because how the condition of the elderly in enjoying their old age is determined by their lifestyle in the past. Based on Law No. 13 of 1998 concerning the welfare of the elderly, it stipulates that the age limit for the elderly in Indonesia is 60 years and over. The elderly is closely related to the decline in all organ functions, which can occur physiologically, normally or pathological. Including the risk of developing dental infectious diseases in the oral cavity, such as dental caries and periodontitis which are the main factors causing tooth loss. Wanda (2008)

Tooth loss in the elderly is not only interfering with the function of phonetics, esthetic, mastication and nutritional status, but also has an effect on cognitive function. Carr (2015), Dosumu et al. (2014), Hansson et al. (2013) Many mechanisms link cognitive function and the state of a person's teeth. When a person experiences a 
lot of tooth loss, he will tend to choose a soft diet which results in lower nutrient intake than natural teeth. It should be noted that when mastication occurs, neuronal activity and the hippocampus are stimulated, which are important in maintaining cognitive function. When mastication is impaired due to tooth loss, sensory input is reduced from periodontal mechanoreceptors (PDMs). Hansson et al. (2013) This sensory input may decrease as the number of teeth decreases. Miyamoto et al. (2005)

Several studies, examining the relationship between natural teeth, masticatory disorders, and cognitive function have yielded similar results. One interpretation of this finding is that reduced sensory input from periodontal mechanoreceptors (PDMs) via the trigeminal sensory nerve results from tooth loss. This affects the function of the hippocampus, resulting in decreased cognitive function. Miyamoto et al. (2005)

The hippocampus is sensitive to stress and the aging process. It can stimulate the hypothalamic-pituitary-adrenal (HPA) axis, causing the pituitary gland to secrete an adrenocorticotrophic hormone (ACTH). An increased ACTH concentration will cause the adrenal cortex to secrete corticosterone. The increase of corticosterone concentrations suppresses hippocampus-dependent learning and memory. Kataoka et al. (2008)

Cognitive function can be seen by using the MMSE questionnaire. The results of research by Hanson, et al., and Nazomi, et al., show that the fewer teeth that remain in the oral cavity, the lower the cognitive function. Hansson et al. (2013), Okamoto et al. (2011) However, it should be noted that tooth loss is not the only factor associated with cognitive decline. There are several other factors related to cognitive function, namely physical activity, education level, disease history, nutritional status, smoking history, other factors including sleep disorders, head injuries, and depression. Hansson et al. (2013)

Nursing house are a place for the elderly to continue to live comfortably. In Banda Aceh, there is only one nursing house, in Lamgeulumpang Village, Ulee Kareng, Banda Aceh City, which until now is under the UTD Social Service. Based on the description above, researchers are interested in knowing the overview of cognitive function (MMSE) in the elderly with variations in the remaining teeth.

\section{METHOD}

This research took 19 days at The Geunaseh Sayang Nursing Home, Gampong Lamgeulumpang, Banda Aceh City. This type of research is clinical research with a cross-sectional research design. The sampling method was carried out by total sampling involving 57 subjects from the elderly.

The targeted subjects for this study were the elderly 60 years old who stayed in the Geunaseh Sayang Nursing Home, Banda Aceh. Subject selection was done by the purposive sampling technique. Before conducting the research, the subjects were selected beforehand by conducting interviews based on the inclusion and exclusion criteria as well as several factors involved in this study. Next, the researcher provides information about what will be done to the research subject. Research subjects who meet the inclusion criteria and are willing to participate in the study can sign an informed consent.

\section{Intra-Oral Examination}

The intra-oral examination was performed to see the amount of tooth loss and the location of the tooth loss. This examination is performed using a mouth mirror. 
Before the examination, the researcher fulfilled the universal precaution first, by using a mask and medical gloves. Research subjects were seated in a position facing the light source (flashlight). Then the research subjects were asked to open their mouths. Dental observations were carried out using a mouth mirror. A mouth mirror is used to draw the corners of the mouth and see the amount of tooth loss. The examination started from the right maxillary teeth to the left maxillary teeth, and continued to the left lower jaw and then to the right lower jaw. The results of the intra-oral examination were recorded on the examination sheet with the category of the number of teeth remaining in the oral cavity, namely category I $(0$ 10), category II (11-21), and category III (22-31).

\section{Cognitive Function Examination}

Cognitive function examination using the MMSE questionnaire. The MMSE test is used as a tool to detect cognitive disorders. The MMSE examination includes assessment of orientation, registration, attention, and calculation, recall test, and language. The MMSE test adopts an interview system where the research subject responds to the researcher's direction and the results are recorded in the MMSE questionnaire by the researcher. The results of the study are the state of cognitive function in the following numerical scale: Galea and Woodward (2005)
1) Severe cognitive impairment :0-17
2) Mild cognitive impairment :18-23
3) Normal cognitive function :24-30

\section{Data analysis}

The data that has been collected will be processed using the Microsoft Excel (2010) program. Presentation of data using bar charts and tabulation tables to see an overview of cognitive function on the number of tooth loss in the elderly at the Geunaseh Sayang Nursing House, Banda Aceh.

\section{RESULTS}

The subjects in this study were the elderly at the Geunaseh Nursing House. The number of subjects in this study was 43 subjects with female subjects dominating than male subjects. This study was carried out using interviews, questionnaires, and intra-oral examination to see the number of remaining teeth in the oral cavity. From 43 elderly people, cognitive function overview with variations in the remaining teeth showed that the more remaining teeth in the oral cavity, the better their cognitive function. On the other hand, the fewer remaining teeth, the lower their cognitive function.

\section{Descriptive Analysis}

\begin{tabular}{|cc|}
\hline Table 1 Characteristics of Research Subjects & \\
\hline Characteristics of Research Subjects (n=43) & (\%) \\
\hline Age (Mean; SD) & 70 years; 6.2 \\
\hline Gender & \\
\hline Female (n=26) & 60.5 \\
Male (n=17) & 39.5 \\
Level of education & \\
\hline Not attending school (n=12) & 27.9 \\
\hline Elementary School/ equivalent $(\mathrm{n}=12)$ & 27.9 \\
\hline
\end{tabular}




\begin{tabular}{|c|c|}
\hline Junior high school/ equivalent $(n=8)$ & 18.6 \\
\hline Senior high school/ equivalent $(n=6)$ & 14 \\
\hline Undergraduates $(n=5)$ & 11.6 \\
\hline \multicolumn{2}{|l|}{ Illness } \\
\hline Diabetes Mellitus $(n=10)$ & 23.2 \\
\hline Hypertension $(\mathrm{n}=18)$ & 41.9 \\
\hline Heart Disease $(n=7)$ & 16.3 \\
\hline \multicolumn{2}{|l|}{ Smoking History } \\
\hline Previously Smookers (n=4) & 9.3 \\
\hline Smokers $(\mathrm{n}=8)$ & 18.6 \\
\hline Never Smoked (n=31) & 72.1 \\
\hline \multicolumn{2}{|l|}{ Physical Activity } \\
\hline$>30$ minutes a day $(n=29)$ & 67.4 \\
\hline$<30$ minutes a day $(n=14)$ & 32.6 \\
\hline \multicolumn{2}{|l|}{ Nutritional Status (MNA) } \\
\hline Malnutrition $(\mathrm{n}=10)$ & 23.2 \\
\hline Malnutrition Risk (n=19) & 44.2 \\
\hline Normal $(n=14)$ & 32.6 \\
\hline \multicolumn{2}{|l|}{ Other Factors } \\
\hline Depression $(n=8)$ & 18.6 \\
\hline No Depression $(n=35)$ & 81.4 \\
\hline History of Head Injury $(n=15)$ & 34.8 \\
\hline No Head Injury $(n=28)$ & 65.2 \\
\hline Sleep Disorders (n=19) & 44.1 \\
\hline No Sleep Disorders $(n=24)$ & 55.8 \\
\hline
\end{tabular}

Table 1 shows the characteristics of the research subjects. From Table 1, it shows that the average age of the elderly is 70 years, dominated by $60.5 \%$ female subjects. Of the five levels of education in Table 1, most of the subjects did not go to school and elementary school/equivalent. The history of the disease showed that hypertension was the most common in the research subjects, followed by diabetes mellitus, and heart disease. The results of the study showed that most of the subjects had never smoked. The elderly who did the planting, cleaning the yard, washing clothes, or other physical activities with a duration of $>30$ minutes was more than the elderly who did less than 30 minutes of physical activity. The nutritional status of the elderly shows that many elderlies have a risk of malnutrition. In addition, most of the subjects showed no depression, no head injury, and no sleep disturbances.

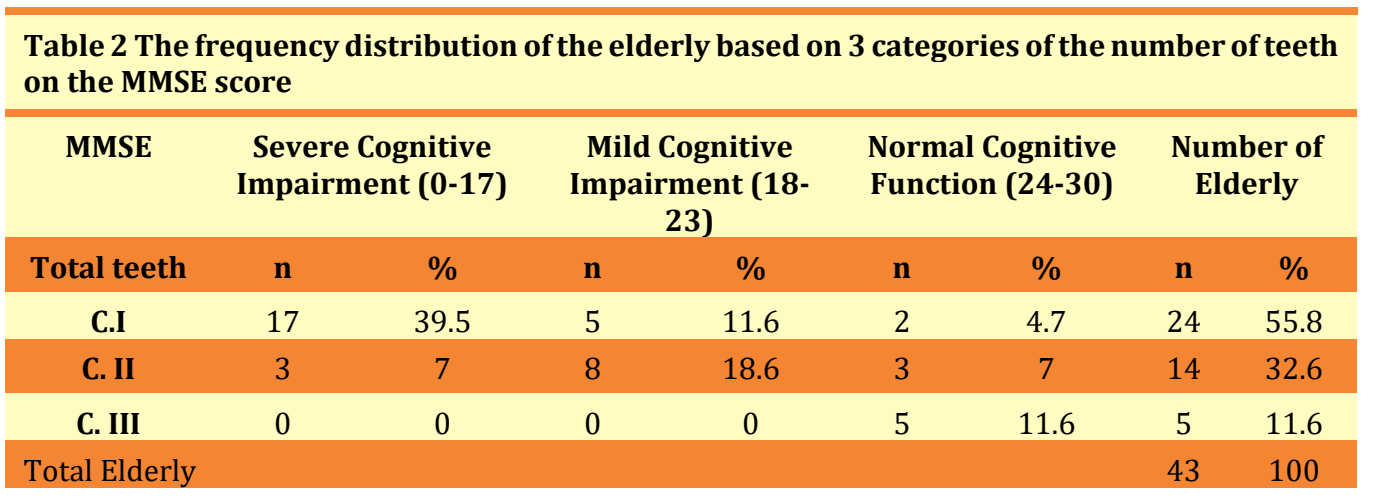


Table 2 shows that of the 24 subjects with category I, the research subjects with severe cognitive impairment were 17 subjects (39.5\%), in addition, 5 subjects (11.6\%) with mild cognitive impairment, and the elderly with normal cognitive function were $2(4.7 \%)$. Furthermore, from 14 subjects with category II, research subjects with severe cognitive impairment showed the same results in subjects with normal cognitive, contributed 3 subjects (7\%), subjects with mild cognitive impairment totaling 8 elderly (18.6\%). Furthermore, from the 5 total subjects with category III, all subjects with normal cognitive function were 5 elderly $(100 \%)$. This distribution can be seen in graph 1 below.

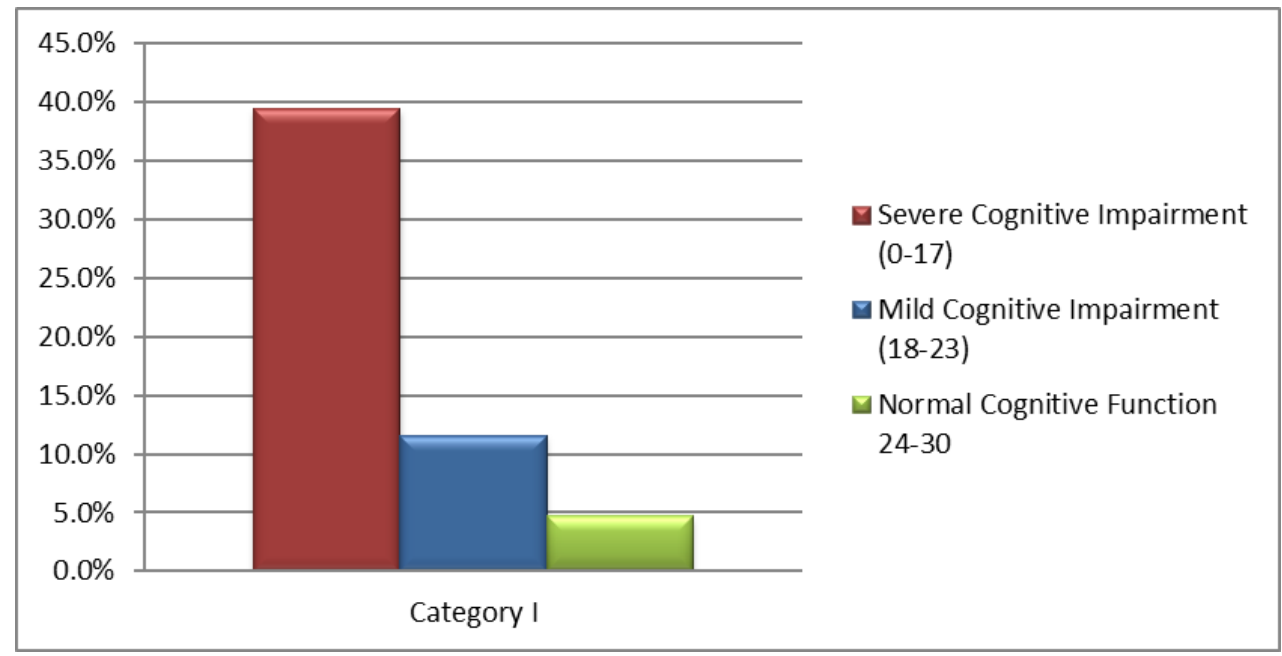

Figure 1 Frequency distribution of elderly category I to the MMSE score

Figure 1 shows the variation in the distribution of MMSE scores in category I. A score of 0-17 (severe cognitive impairment) dominates with a percentage of 39.5\%, followed by a score of $18-23$ (mild cognitive impairment) as much as $11.6 \%$, and a score of 24-30 (normal cognitive impairment) as much as $4.7 \%$.

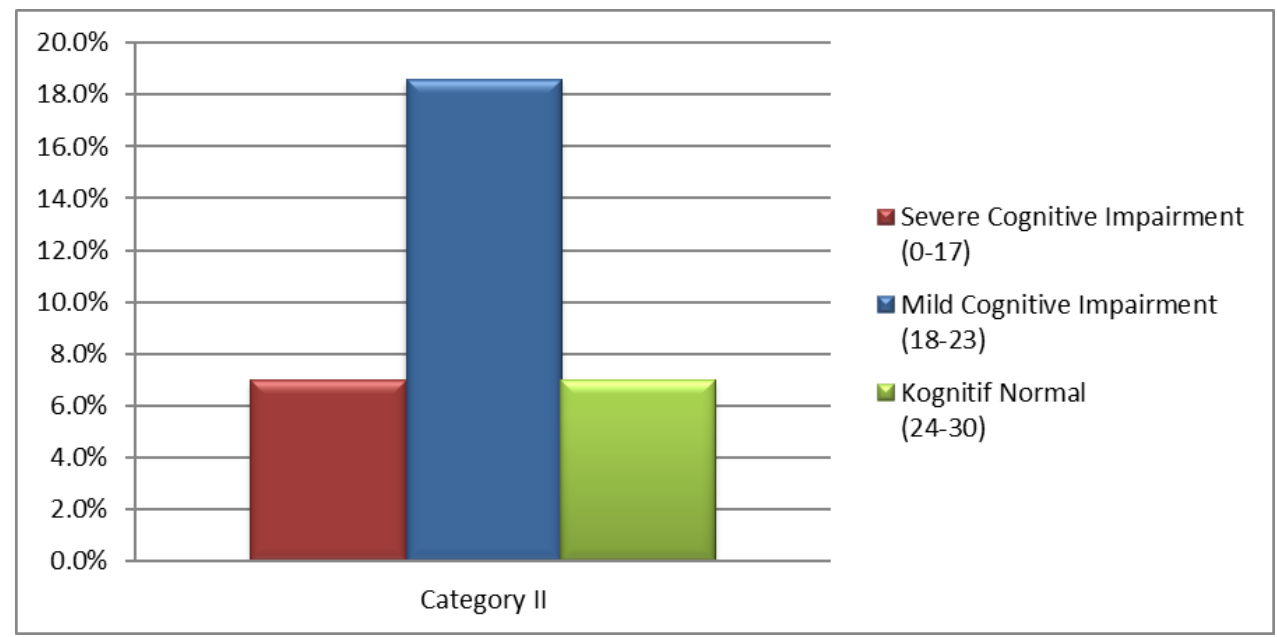

Figure 2 Frequency distribution of elderly category II to the MMSE score

Figure 2 shows that the distribution of MMSE scores is based on category II. In this category, the MMSE score of 0-17 with severe cognitive impairment showed the 
same results as the MMSE score of 24-30, which was 7\%, then the score of 18-23 showed the highest percentage, which was $18.6 \%$.

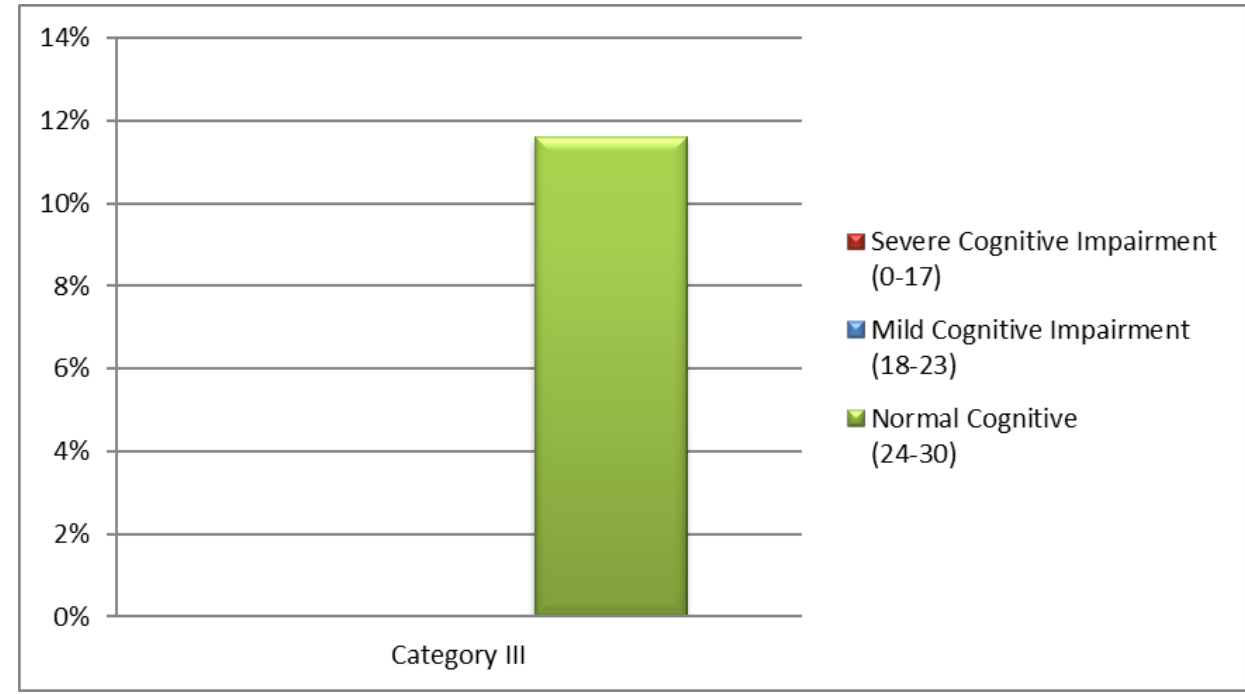

Figure 3 Frequency distribution of elderly category III to the MMSE score

Figure 3 shows that there is no distribution of research subjects on the MMSE score of 0-17 and the MMSE score of 18-23. While the score of 24-30 includes all subjects in category III, showing a percentage of $11.6 \%$.

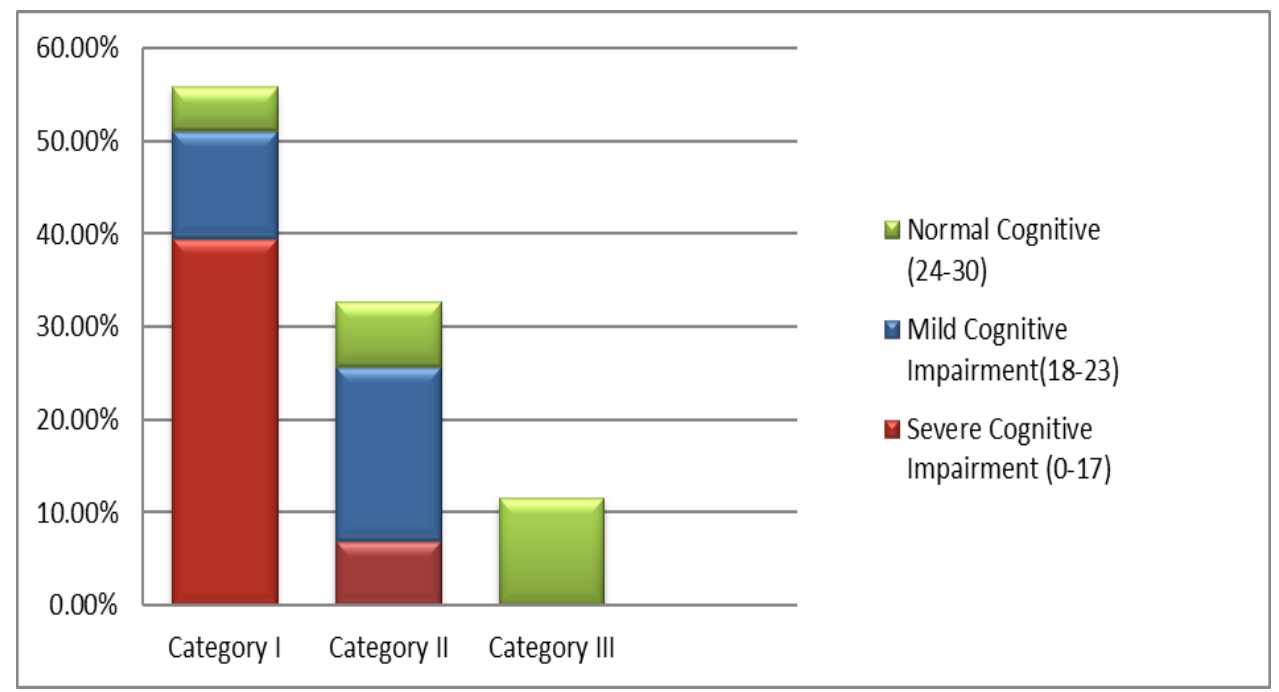

Figure 4 Frequency distribution of the number of teeth categories on the MMSE score

Figure 4 illustrates the conclusions of the research results from graphs 1,2, and 3 , which show the frequency distribution of all categories of remaining teeth to the MMSE score, which is detailed in Table 2. Variations in results in each category of elderly can be assumed to be related to the involvement of cognitive-related factors. which is described in Table 3 below. 


\begin{tabular}{|c|c|c|c|c|c|c|}
\hline \multirow[t]{2}{*}{$\begin{array}{l}\text { Factors Affecting Cognitive } \\
\text { Function }(n=43)\end{array}$} & \multicolumn{2}{|c|}{$\begin{array}{l}\text { Severe Cognitive } \\
\text { Impairment }(0-17)\end{array}$} & \multicolumn{2}{|c|}{$\begin{array}{c}\text { Mild Cognitive } \\
\text { Impairment (18-23) }\end{array}$} & \multicolumn{2}{|c|}{$\begin{array}{c}\text { Normal } \\
\text { Cognitive } \\
(24-30)\end{array}$} \\
\hline & $\mathbf{n}$ & $\%$ & $\mathbf{n}$ & $\%$ & $\mathbf{n}$ & $\%$ \\
\hline \multicolumn{7}{|c|}{ Level of education } \\
\hline Not attending school $(\mathrm{n}=12)$ & 9 & 20.9 & 3 & 7 & 0 & 0 \\
\hline $\begin{array}{ll}\text { Elementary } & \text { School/ } \\
\text { equivalent }(n=12) & \end{array}$ & 4 & 9.3 & 5 & 11.6 & 3 & 7 \\
\hline $\begin{array}{l}\text { Junior high } \quad \text { school/ } \\
\text { equivalent }(n=8)\end{array}$ & 2 & 4.6 & 3 & 7 & 3 & 7 \\
\hline $\begin{array}{l}\text { High School/ equivalent } \\
(n=6)\end{array}$ & 1 & 2.3 & 5 & 11.6 & 0 & 0 \\
\hline Undergraduates $(n=5)$ & 0 & 0 & 1 & 2.3 & 4 & 9.3 \\
\hline \multicolumn{7}{|c|}{ Illness } \\
\hline Diabetes Mellitus $(n=10)$ & 1 & 2.3 & 5 & 11.6 & 4 & 9.3 \\
\hline Hypertension $(\mathrm{n}=18)$ & 7 & 16.3 & 6 & 13.9 & 5 & 11.6 \\
\hline Heart Disease $(n=7)$ & 2 & 4.6 & 2 & 4.6 & 3 & 7 \\
\hline \multicolumn{7}{|c|}{ Smoking History } \\
\hline Previously $(\mathrm{n}=4)$ & 4 & 9.3 & 0 & 0 & 0 & 0 \\
\hline Smokers $(\mathrm{n}=8)$ & 1 & 2.3 & 4 & 9.3 & 3 & 7 \\
\hline Never Smoked $(n=31)$ & 11 & 25.6 & 13 & 30.2 & 7 & 16.3 \\
\hline \multicolumn{7}{|c|}{ Physical Activity } \\
\hline$>30$ minutes $(n=29)$ & 9 & 20.9 & 14 & 32.5 & 6 & 14 \\
\hline$<30$ minutes $(\mathrm{n}=14)$ & 7 & 16.3 & 3 & 7 & 4 & 9.3 \\
\hline \multicolumn{7}{|c|}{ Nutritional Status (MNA) } \\
\hline Malnutrition $(n=10)$ & 8 & 18.6 & 1 & 2.3 & 1 & 2.3 \\
\hline Malnutrition Risk $(n=19)$ & 10 & 23.3 & 8 & 18.6 & 1 & 2.3 \\
\hline Normal $(n=14)$ & 2 & 4.7 & 4 & 9.3 & 8 & 18.6 \\
\hline \multicolumn{7}{|c|}{ Other Factors } \\
\hline Depression $(\mathrm{n}=8)$ & 7 & 16.3 & 1 & 2.3 & 0 & 0 \\
\hline No Depression $(n=35)$ & 9 & 20.9 & 16 & 37.2 & 10 & 23.3 \\
\hline $\begin{array}{l}\text { History of Head Injury } \\
(n=15)\end{array}$ & 9 & 20.9 & 5 & 11.6 & 1 & 2.3 \\
\hline No Head Injury $(n=28)$ & 7 & 16.3 & 12 & 27.9 & 9 & 20.9 \\
\hline Sleep Disorders (n=19) & 6 & 13.9 & 9 & 20.9 & 4 & 9.3 \\
\hline No Sleep Disorders $(n=24)$ & 10 & 23.3 & 8 & 18.6 & 6 & 13.9 \\
\hline
\end{tabular}

Table 3 shows that in the history of education level, there are 5 variations in the level of education, namely not attending school, elementary school/equivalent, junior high school/equivalent, high school/equivalent, D3-S1. The history of the disease suffered by the research subjects showed that hypertension had the most distribution compared to diabetes mellitus and heart disease.

Table 3 also mentions the smoking history of the research subjects based on the MMSE score. Smoking history was divided into 3 categories, namely smokers, never smoked, and former smokers. In subjects who were formerly smokers, the MMSE score of 0-17 (severe cognitive impairment) was 4 elderly with a percentage of 9.3\%. There was no distribution of subjects who had smoked for a score of 18-23 (mild cognitive impairment) and a score of 24-30 (normal cognitive). The frequency distribution of the duration of physical activity is described in table 5.3. showed that 
the elderly who did physical activity $>30$ minutes per day showed an MMSE score of 0-17 (severe cognitive impairment) totaling 9 subjects with a percentage of $20.9 \%$. The score of 18-23 (mild cognitive impairment) was 14 with a percentage of $32.5 \%$, and a score of 24-30 (normal cognitive) was 6 subjects with a percentage of $14 \%$. Meanwhile, research subjects who did physical activity $<30$ minutes showed that the MMSE score was 0-17 (severe cognitive impairment).

The results of the nutritional status of the research subjects based on Table 3 show that of the 20 subjects with severe cognitive impairment, 8 elderly were malnourished, 10 elderly were at risk of malnutrition and 2 elderly showed normal nutritional status. Meanwhile, of the 13 subjects with mild cognitive impairment, 8 elderly subjects were at risk of malnutrition, followed by 4 subjects with normal nutritional status, and 1 subject with malnutrition. Despite of 10 subjects with normal cognitive, there are 8 elderly with normal nutritional status and 1 elderly each with malnutrition and the risk of malnutrition.

Furthermore, the distribution of depression factors based on the MMSE score showed that the MMSE score 0-17 (severe cognitive impairment) consisted of 7 subjects with a percentage of $16.3 \%$. The MMSE score of 18-23 (mild cognitive impairment) totaling 1 subject with a percentage of $2.3 \%$, and a score of 24-30 (normal cognitive) amounted to 0 subjects. While the research subjects who did not have depression showed that the MMSE score 0-17 (severe cognitive impairment) amounted to 9 subjects with a percentage of 20.9\%. The MMSE score of 18-23 (mild cognitive impairment) totaled 16 subjects with a percentage of $37.2 \%$, and a score of 24-30 (normal cognitive) amounted to 10 subjects with a percentage of $23.3 \%$.

\section{DISCUSSION}

The tooth loss can affect not only general health and nutritional status but is also associated with a decline in cognitive function. Paganini-Hill et al. (2011) Characteristics of the results obtained that the average age of the elderly is 70 years and from the results of the study elderly women (60.5\%) occupy more positions than elderly men (39.5\%). Please note that the hippocampus is a brain organ that is sensitive to stress and the aging process because it can stimulate the HPA (hypothalamus-pituitary-adrenal) axis, which makes the pituitary gland produce adrenocorticotropic hormone (ACTH). If the HPA axis continues to produce ACTH, the concentration of ACTH in the body increases, causing the adrenal cortex to secrete corticosterone, and the target for corticosterone is the hippocampus. Thus, the increase in the concentration of corticosterone suppresses the work function of the hippocampus which resulted in a decrease in cognitive function. Kataoka et al. (2008)

The quality of cognitive function in research subjects shows using the MMSE questionnaire. The MMSE questionnaire classified five cognitive abilities, namely orientation ability, registration ability, attention and calculation ability, recall ability, and language ability. Various studies have shown that tooth loss is positively associated with cognitive decline. Based on the results shown in Table 2, the elderly was divided into several groups based on the number of teeth that were still left in the oral cavity. The number of teeth that remain in the oral cavity is a sign of impaired cognitive function. It is noteworthy that the elderly with a slight variation in the remaining teeth affects masticatory function. Various studies conducted using fMRI (Functional Magnetic Resonance Imaging) and PET (Positron Emission Tomography) have displayed an increase in blood flow and oxygen levels in the prefrontal cortex and hippocampus during mastication. Seraj et al. (2017), Kawasaki et al. (2009) When masticatory function decreases, this experience will decline the 
number of pyramidal cells and the level of acetylcholine in the hippocampus, which causes impaired cognitive function. Okamoto et al. (2011), Kawasaki et al. (2009)

Table 2 has been pointed out the overall results of the three categories of research subjects on the MMSE score, showing significant results for each cognitive function criterion. This condition occurs because when a person loses a tooth, the sensory input is decreased from the periodontal mechanoreceptors (PDMs). Hansson et al. (2013), Miyamoto et al. (2005) This decreased sensory input then affects the work of the hippocampus, an important organ responsible for cognitive function. Hansson et al. (2013) The more teeth lost, the more the sensory input of periodontal mechanoreceptors (PDMs) reduced, resulting in decreased cognitive function. The results of this study are related to Hanson, et al., and Nazomi, et al. which state that the more teeth you lose, the lower your cognitive function will be. Hansson et al. (2013), Miyamoto et al. (2005)

Although the research subject category shows significant research results on the MMSE score, it is crucial to note that each subject usually has other risk factors related to cognitive function. The results of this study also discuss factors related to cognitive function. This factored-in shows why not all categories of elderly displayed a percentage (100\%) of certain MMSE scores. Various factors related to the cognitive function shown in Table 3 included the subject's illness, education level, duration of physical activity per day, smoking history, nutritional status, sleep disorders, head injury, and depression are factors that have been studied previously by various studies. All of those factors show a relationship to cognitive function. Hansson et al. (2013), Gatz et al. (2006), Baumgart et al. (2015)

The results of this study revealed that the elderly who did not go to school and graduated from elementary school/equivalent experienced a decrease in cognitive function more than the elderly with a higher level of education. It can be understood through mechanisms to maximize the function of the brain, which is in the process of learning can delay the degeneration process that lasts because physiological effects and activates mental activity. Research conducted by Gatz, et al., that the longer a person's education period, the higher the mental activity. The effects of mental activity can increase the density of brain synapses. Gatz et al. (2006) While the research Baumgart, et al., Mention that people with many years of formal education have a lower risk of cognitive impairment compared to those with less formal education. Baumgart et al. (2015)

The distribution of history of illness (81.4\%) included hypertension (41.9\%), followed by diabetes mellitus (23.2\%), and heart disease (16.3\%). Long-term hypertension increases arterial stiffness, leading to severe cerebral atherosclerosis. Atherosclerotic and hemodynamic mechanisms related to hypertension will contribute to the early expression of Alzheimer's disease by inducing vascular changes, high blood pressure can also damage the blood and brain barrier, increase vascular permeability, and extravasation of proteins in the cerebral parenchyma. This dysfunction will result in the accumulation of amyloid which results in cognitive decline. However, people with hypertension who take antihypertensive drugs regularly can eventually protect and prevent cognitive function. Rouch et al. (2015)

Based on several meta-analyses, and recent systematic studies have shown low cognitive function scores in individuals with diabetes resulting in an increased risk of dementia. Baumgart et al. (2015) In this case it is explained that in the brain, insulin is involved in various cognitive functions. A large number of insulin receptors are located in the hippocampus and cerebral cortex, which play a central role in memory. Insulin induces the release of amyloid peptide (Ab) to the outside of the cell, and also increases the expression of IDE (Insulin-Degrading Enzyme). IDE 
is also involved in Ab degradation. So, the lack of insulin will increase the risk of accumulation of $\mathrm{Ab}$ which causes the cognitive function to decline. Gudala et al. (2013) Moreover, in the case of hyperinsulinemia or insulin resistance, decreased insulin receptors, thereby decreasing insulin levels to the brain. Also, in the state of hyperinsulinemia, the amount of IDE decreases due to its higher consumption, resulting in an increase in $\mathrm{Ab}$ leading to accelerated cognitive decline. Young et al. (2006) In the study of Hisayama et al., autopsy findings showed that hyperinsulinemia and hyperglycemia increase the formation of neuritic plaques that lead to cognitive decline. Matsuzaki et al. (2010)

Heart disease shows an association with impaired cognitive function as shown in Table 3 of 7 the number of subjects with heart disease, there are 4 subjects with cognitive impairment. This condition able to occur because heart disease and accompanying vascular insufficiency can cause cerebrovascular changes such as reduced cerebral blood flow (which can lead to hypoperfusion), white matter lesions, and brain infarction, which are associated with decreased cognitive function and the risk of dementia. Deckers et al. (2017)

In relation to smoking history in Table 3 , the results of the distribution of smoking history to the MMSE score in Table 3 are that the elderly who do not smoke show more cognitive disorders. This is in contrast to research conducted by Baumgart, et al., who found strong evidence that smoking increases the risk of cognitive decline and the likelihood of dementia. Quitting smoking can reduce the risk of cognitive decline compared to those who have not smoked. Gatz et al. (2006) Meanwhile, in the study of Peters, et al., smoking can accelerate cerebral atrophy, decreased perfusion, and white matter lesions. Subjects who had previously smoked had a lower risk than smokers for Alzheimer's disease and cognitive decline. Peters et al. (2008) The discrepancy with existing research, can be assumed by the involvement of other factors that influence the cognitive function of each subject in this research.

The elderly who lives in nursing house can carry out activities or hobbies such as farming, cleaning the yard, sewing clothes, washing clothes, going to the prayer room for congregational prayers and recitations, even going to the market. The elderly is allowed to do activities outside the nursing house once a week and the elderly can participate in gymnastics activities every Thursday held by the nursing house committee. The characteristics of the research subjects in Table 1 show that the duration of physical activity $>30$ minutes $(67.4 \%)$ is more dominant than the duration of physical activity $<30$ minutes $(32.6 \%)$. Table 3 shows the distribution of research subjects to the MMSE score which shows that the duration of physical activity $>30$ minutes indicates better cognitive function. This condition occurs because physical activity is known to play an important role in protecting against cognitive decline through the process of neuroplasticity. The phenomenon of neuroplasticity determines structural changes such as increased gray matter volume in the frontal and hippocampus regions and reduced gray matter damage. In addition, physical activity facilitates the release of neurotrophic factors such as peripheral BDNF, improves cerebrovascular health, and carries nutrients to the brain. Mandolesi et al. (2018)

Associated with tooth loss experienced by the elderly, allows the tendency of the elderly to choose foods that are soft or easy to chew. A study revealed that losing teeth will cause nutritional adequacy to be disrupted. Jae-Mae et al. (2007) From the results of the study in Table 3 , we can conclude that subjects with malnutrition and at risk of malnutrition show cognitive impairment, while subjects with normal nutritional status are dominated by subjects with normal cognitive (24-30). This can occur because nutrients in the elderly unfulfilled essential foods that petrify various 
brain processes by regulating neurotransmitter pathways, synaptic transmission, membrane fluidity, and signal transduction pathways. Especially, it is the effect of oxidative damage on the brain, where it is important the needs of vitamins $\mathrm{C}, \mathrm{E}$, and carotene. Many studies also mention the importance of eating foods with omega-3 fatty acids and vitamins B6, B12, and folate in preventing cognitive impairment. Ramachandran et al. (2018) Several studies have shown the same result that individuals with cognitive impairment are characterized by poor nutritional status. Hai et al. (2017)

Table 2 shows that of the 8 subjects who experienced depression, 7 experienced severe cognitive impairment. According to research conducted by Hermida, et al., stated that depression is a prodromal clinical phase of neurodegenerative changes that occur in Alzheimer's disease. However, depression as a risk factor for Alzheimer's disease was refuted. Interestingly, depression, dementia, and MCI showed some of the same findings, namely lower hippocampal volume, vascular changes in the brain, and neurotransmitter deficits. Hermida et al. (2012) Oral health can affect mental health just as mental health can affect oral health. Sko et al. (2018) Research by Dahl, et al., states that the higher the level of psychological stress, the higher the oral health of the elderly. Dahl (2018) A study conducted by Kim et al., reported that more severe depression was detected in patients with many teeth that had decayed caries and few teeth that were restored. Wennberg et al. (2017) In addition, problems with chewing or difficulty speaking cause stress and depression. Sko et al. (2018) Biological and behavioral mechanisms explaining the correlation between depression and oral health. The increased severity of depression associated with poorer oral hygiene is due to reduced salivary secretion and increased lactobacillus counts, which are side effects of antidepressants. Sko et al. (2018)

The history of head injury of research subjects shown in Table 1 is less distributed than research subjects who have a head injury history. The relationship of a history of head injury to the MMSE score shown in Table 3 shows that the more research subjects who have a head injury history, the worse their cognitive function. This happens because those who experience persistent head injuries (for example boxers, soccer players, and war soldiers) are at a higher risk. Although it is unknown what specific aspects of head injury (strength, repetition, etc) cause impaired brain function, several studies have combined a history of head injury with an increased risk of cognitive decline and dementia. Baumgart et al. (2015)

The distribution of research subjects on sleep disorders in Table 1 shows a smaller percentage compared to the distribution of study subjects without sleep disorders. This is due to the uneven distribution of subjects. The relationship between sleep disturbances and MMSE scores shown in Table 3 shows that sleep disturbances include the distribution of cognitive function disorders. This is reinforced by the results of research by Alexander, et al., $60 \%-70 \%$ of people with cognitive impairment or dementia have sleep disorders. Wennberg et al. (2017) In various cross-sectional studies, sleep duration of fewer than 5 hours and more than 11 hours per night, poor sleep quality, prolonged sleep, increased wakefulness during sleep, increased nap time were associated with an increased risk of cognitive impairment. Sleep disturbances increase the accumulation of Amyloid- $\beta$ (Amyloid plaques) which can decrease neurocognitive function. Lucey and Holtzman (2014)

\section{CONCLUSION}

The overview of cognitive function in the elderly with variations of total remaining teeth shows that in category I the elderly are dominated by severe cognitive disorders, while in category II the elderly is dominated by mild cognitive 
disorders, and in category III shows the overall distribution of subjects with normal cognitive. The results showed an overview of cognitive function based on contributed factors to cognitive function, namely education history, diabetes mellitus, hypertension, heart disease, physical activity, nutritional status, depression, history of head injury. The other factors that showed discrepancies in the results on cognitive function included a history of smoking and a history of sleep disorders.

\section{REFERENCES}

Baumgart M, Snyder HM, Carrillo MC, Fazio S, Kim H, Johns H. (2015) Summary of The Evidence on Modifiable Risk Factors For Cognitive Decline and Dementia: A Population-Based Perspective. Alzheimer's Dement.11(6):720. Retrieved from https://doi.org/10.1016/j.jalz.2015.05.016

Carr, Alan B DTB-M. (2015) Partially Edentulous Epidemiology, Physiology, and Terminology in Removable Partial Prosthodontics. 13th Editi. Mosby: Elsevier. 5 p.

Dahl KE, Calogiuri G JB. (2018) Perceived Oral Health and Its Association with Symptoms of Psychological Distress, Oral Status and Socio-Demographic Characteristics Among Elderly in Norway. BMC Oral Health.1(18):93. Retrieved from https://doi.org/10.1186/s12903-018-0556-9

Deckers K, Schievink SHJ, Rodriquez MMF, Van Oostenbrugge RJ, Van Boxtel MPJ, Verhey FRJ, et al. (2017) Coronary Heart Disease and Risk For Cognitive Impairment or Dementia: Systematic Review and Meta-Analysis. PLoS One.12(9):11. Retrieved from https://doi.org/10.1371/journal.pone.0184244

Dosumu 00, Ogunrinde JT, Bamigboye SA. (2014) Knowledge of Consequences of Missing Teeth in Patients Attending Prosthetic Clinic. Ann Ibadan Postgrad Med.12(1):42;43.

Retrieved from https://www.ajol.info/index.php/aipm/article/view/107710

Galea M, Woodward M. (2005) Mini-Mental State Examination (MMSE): Commentary. Aust J Physiother.51(3):2. Retrieved from https://doi.org/10.1016/S0004-9514(05)70034-9

Gatz J.A., Mortimer L., Fratiglioni B., Johansson S., Berg C.A. R. (2006) Potentially Modifiable Risk Factors for Dementia in Identical Twins. Vol. 2, Alzheimer's and Dementia. p. 111. Retrieved from https://doi.org/10.1016/j.jalz.2006.01.002

Gudala K, Bansal D, Schifano F, Bhansali A. (2013) Diabetes Mellitus and Risk of Dementia: A Meta-Analysis of Prospective Observational Studies. I:8. Retrieved from https://doi.org/10.1111/jdi.12087

Hai S, Cao L, Yang X, Wang H, Liu P, Hao Q, et al. (2017) Association Between Nutrition Status and Cognitive Impairment Among Chinese Nonagenarians and Centenarians. Int J Gerontol.11(4):217. Retrieved from https://doi.org/10.1016/j.ijge.2016.12.002

Hansson P, Sunnegårdh - Grönberg K, Bergdahl J, Bergdahl M, Nyberg L, Nilsson LG. (2013) Relationship between natural teeth and memory in a healthy elderly population. Eur J Oral Sci.121(4):333;339. Retrieved from https://doi.org/10.1111/eos.12060

Hermida AP, Mcdonald WM, Steenland K. (2012) The Association Between Late- Life Depression, Mild Cognitive Impairment and Dementia : Is Inflammation The 
Missing Link? Expert Rev Neurother.12(11):1339. Retrieved from https://doi.org/10.1586/ern.12.127

Jae-Mae Kim, Robert Stewart, Martin Prince, Sung-Wan Kim, Yang, Su-Jin Shin, IlSeon Yoon and J-S. Dental (2007) Health, Nutritional Status, and RecentOnset Dementia in An Korean Community Population. Int J Geriatr Psychiatry.22(9):853. Retrieved from https://doi.org/10.1002/gps.1750

Kataoka T, Tachibana A, Ono Y, Sasaguri K-I, Miyake S, Cheng S-J, et al. (2008) Chewing Ameliorates Stress-Induced Suppression of Hippocampal LongTerm Potentiation. Neuroscience.154(4):1352. Retrieved from https://doi.org/10.1016/j.neuroscience.2008.04.057

Kawasaki S, Matsumoto T, Narita N, Kamiya K, Tanaka N, Yamamura K. (2009) Chewing-Related Prefrontal Cortex Activation While Wearing Partial Denture Prosthesis: Pilot Study. J Prosthodont Res.53(3):127. Retrieved from https://doi.org/10.1016/j.jpor.2009.02.005

Lucey BP, Holtzman DM. (2014) Sleep and Alzheimer Disease Pathology-A Bidirectional Relationship. Nat Rev Neurol.10(2):114. Retrieved from https://doi.org/10.1038/nrneurol.2013.269

Mandolesi L, Polverino A, Montuori S, Foti F, Ferraioli G, Sorrentino P, et al. (2018) Effects of Physical Exercise on Cognitive Functioning and Eellbeing: Biological and Psychological Benefits. Front Psychol. 9:2. Retrieved from https://doi.org/10.3389/fpsyg.2018.00509

Matsuzaki T, Sasaki K, Tanizaki Y, Hata J, Fujimi K, Matsui Y, et al. (2010) Insulin Resistance Is Associated with The Pathology of Alzheimer Disease: The Hisayama study. Neurology. 75(9):765. Retrieved from https://doi.org/10.1212/WNL.0b013e3181eee25f

Miyamoto I, Yoshida K, Tsuboi Y, Iizuka T. (2005) Rehabilitation With Dental Prosthesis Can Increase Cerebral Regional Blood Volume. Clin Oral Implants Res.16(6):723. Retrieved from https://doi.org/10.1111/j.16000501.2005.01171.x

Okamoto N, Morikawa M, Okamoto K, Iwamoto J, Tomioka K, Saeki K, et al. (2011) Relationship of Tooth Loss to Mild Memory Impairment and Cognitive Impairment: Findings From the Fujiwara-Kyo Study. J Epidemiol Community Heal.65:2;3;5;6; Retrieved from https://doi.org/10.1186/1744-9081-6-77

Paganini-Hill A, White SC, Atchison KA. (2011) Dental Health Behaviors, Dentition, and Mortality in the Elderly: The Leisure World Cohort Study. J Aging Res.2011:10. Retrieved from https://doi.org/10.4061/2011/156061

Peters R, Poulter R, Warner J, Beckett N, Burch L, Bulpitt C. (2008) Smoking, Dementia and Cognitive Decline in The Elderly, A Systematic Review. BMC Geriatr.7(1):1-2. Retrieved from https://doi.org/10.1186/1471-2318-8-36

Ramachandran R, Mundodan JM, Saju CR, Joshy VM. (2018) Nutritional Status and Cognitive Impairment in Elderly Population in A Rural Area of Thrissur District, Kerala.5(3):1222. Retrieved from https://doi.org/10.18203/23946040.ijcmph20180788

Rouch L, Cestac P, Hanon O, Cool C, Helmer C, Bouhanick B, et al. (2015) Antihypertensive Drugs, Prevention of Cognitive Decline and Dementia: A Systematic Review of Observational Studies, Randomized Controlled Trials and Meta-Analyses, with Discussion of Potential Mechanisms. CNS Drugs.29(2):126. Retrieved from https://doi.org/10.1007/s40263-0150230-6 
Seraj Z, Al-Najjar D, Akl M, Aladle N, Altijani Y, Zaki A, et al. (2017) The Effect of Number of Teeth and Chewing Ability on Cognitive Function of Elderly in UAE: A Pilot Study. Int J Dent.2017 :2-3. Retrieved from https://doi.org/10.1155/2017/5732748

Sko K, Malicka B, Zie M, Kaczmarek U. (2018) Oral Health Condition and Occurance of Depression in Elderly. Wolters Kluwer Heal Inc.97(41):5. Retrieved from https://doi.org/10.1097/MD.0000000000012490

Wanda GC, A WS, (2008) Robert HG. Common Oral Conditions in Older Persons. Am Fam Physician.78(7):845;847-9. Retrieved from https://www.aafp.org/afp/2008/1001/p845.html

Wennberg AMV, Wu MN, Rosenberg PB, Spira AP. (2017) Sleep Disturbance, Cognitive Decline, and Dementia: A Review. Semin Neurol.37(4):396. Retrieved from https://doi.org/10.1055/s-0037-1604351

Young SE, Mainous AG, Carnemolla M. (2006) Hyperinsulinemia and Cognitive Decline in A Middle-Aged Cohort. Diabetes Care.29(12):2691. Retrieved from https://doi.org/10.2337/dc06-0915 